\title{
Providing Integrated Home Care to Elderly in India: An Innovative Entrepreneurial Business Model
}

\author{
Chandrima Chatterjee \\ Doctoral Research Fellow, Indian Institute of Technology, Kharagpur \\ c.chandrima2015@gmail.com
}

\begin{abstract}
Due to changing demographic pattern, India is experiencing rapid population ageing. Population ageing has significant consequences on socio-economic situation of a country. Disability, frailty, comorbidity, poor mental health put pressure not only on the family members of the elderly but also on the entire society. Conversely, some social as well as economic factors have forced many elderly to stay apart from their children. So, for this group of grey population who stays completely alone or with their elder spouse, Integrated Home Care being a combination of both Social and health care is a much needed factor. Although a few private care houses has started their operation in India in recent years, but those care-providing organizations lack several aspects of care giving - usage of modern digital technology is one of them. The present study is based on theoretical model of entrepreneurship and business innovation. In this backdrop, an attempt has been made in this paper to put forward the idea of business canvas model in the context of health care business and to propose a business model for providing integrated home care to elderly cost-effectively in the context of urban India.
\end{abstract}

Keywords: Integrated Home Care, Elderly, Business Canvas model, Digital Technology, Business Innovation.

\section{INTRODUCTION}

Population ageing is a concerning issue globally. Indian population is also rapidly ageing. In India, the elderly population which accounted for $6.7 \%$ of total population in 1991 is expected to increase its share by more than $10 \%$ by the year 2021 as per Census 2011 .About $65 \%$ of the elderly population in India depend on others for performing their day to day activities. The reason is such that almost $72 \%$ elderly men and $65 \%$ elderly female aged 80 years and above are physically immobile. In this context it is also worth mentioning only $20 \%$ of the elderly men and half of the elderly women live with their children (Jeyalakshmi 2011). Lack of social support, depression, chronic disease, fall, poor health was found to be significantly high for those elderly who lived alone. Health care cost is also increasing in leaps and bounce (Mouodi et al 2016). Moreover, elderly generally suffers from chronic diseases. So, providing complete care to this increasing number of elderly specially who are chronically ill at an affordable cost, is a key challenge (Wipro 2012).

\section{LiteratURE REVIEW}

Integrated home care is defined as providing health and social care services to frail elderly in their homes with an objective of increasing the efficiency, coordination and outcome of the care services (Russo et. al 2015, Kodner \& Kyriacou 2000). Principle factors of providing integrated home care successfully are strategic planning, comprehensive service package, patient screening, primary care, Care management, network relationship, teamwork, continuity of coverage and care, information sharing etc. (Kodner \& Kyriacou 2000).In recent years Information and Communication Technology (ICT) has been playing an important role in providing Integrated Home Care (Russo et. al 2015). Tele-monitoring system has already gained popularity in home care service industry (Simmonse et al 2011). In case of comprehensive patient care, tele-monitoring is expected to work best (Madigan et. al. 2013). This system is actually a monitoring service of health conditions of users (Scanaill et al. 2006). Application of this kind of creative information technology may both reduce the cost of providing care (Kimble 2015) and increasing the care-efficiency for home care. Tseng (2007) analysed the use of a particular technology namely Wimax wireless technology in providing health services to ageing society. The study proposed that mobile care service (alternatively known as telemedicare) through Wimax technology is supposed to be ideal for providing home care to elderly. 
Koyamo (2007) proposed the use of 'Caring TV' which is a call-system consisting of a mobile telephone with a picture screen and a picture screen phone. Through 'Caring TV', the elderly person can easily communicate with the caring staff. This system is especially fruitful for those elderly who stays alone in their home. So in order to provide integrative care management, it is necessary to have digital collaboration medium between care providers and care receivers - alert, chart, reminder, SMS, smart phones and tablet PCs, remote patient monitoring devices etc. (WIPRO 2012).

The present study aims at suggesting a useful insight for setting up a business in order to provide integrated home care services to chronically ill elderly. There are a number of business model namely Four-Box Business Model (Johnson 2010), the GRS-model (Verstraete \& Jouison-Laffitte 2011), The Entrepreneur's Business Model (Morris et al. 2005) etc. But Business Canvas Model of Osterwalder \& Pigneur (2009) is found to be more suitable in this context because it contains several relevant components of business and focuses on interrelation between them (Kringelum 2015). It actually describes how a company or entrepreneur creates and delivers value to the potential customer. The model is divided into two parts - one is revenue generating part and another is cost generating one.

\section{Business Model Canvas (BMC) in Health Care: Basic Theory}

On the basis of the theoretical framework as suggested by Osterwalder \& Pigneur (2009), the detailed component of the business canvas model particularly in the perspective of health service management is discussed below.

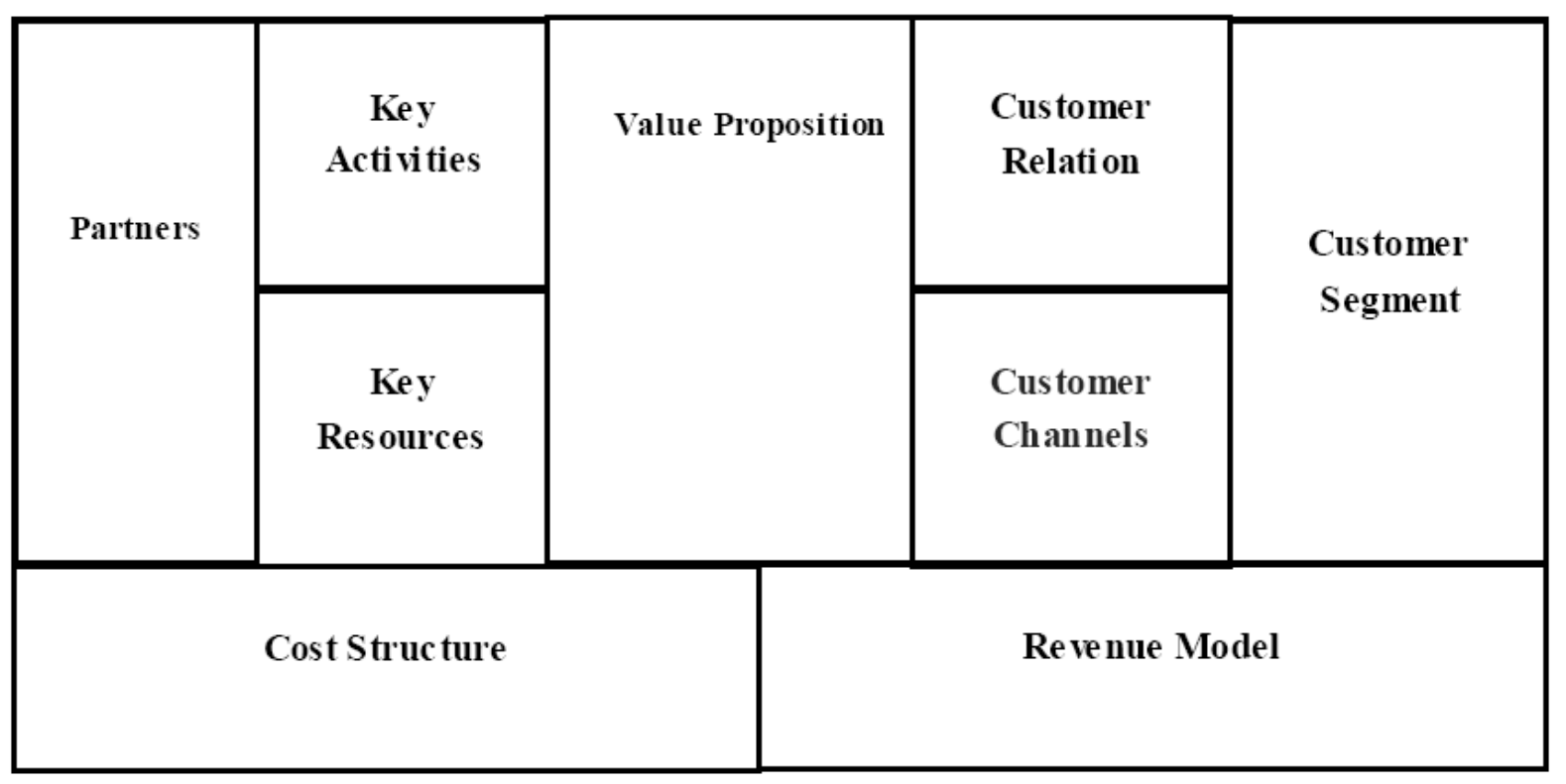

Figure1. Business Model Canvas

The components of BMC are marked in different colours in the figure 1. There are nine components of a BMC model. Those are discussed in detailed below in the context of healthcare business:

(1) Value Proposition

Value proposition refers to the services and resulting benefitted provided to health consumers by the care providers. It deals with certain things such as patient satisfaction, service quality, patient safety, quality management etc. In other words, what the care providers are offering is captured in value proposition. In case of value-based health care, value is measured per patient over a full cycle of care. Output, Outcome and Benefit are the three building blocks of value proposition. Porter (2010) depicted that the value created for the patient in a health care system should benefit all other actor of the system.

\section{(2) Customer Segment}

Customer segment in health care BMC is defined as the type/group of customers those could be involved in the system. It actually means dividing entity into manageable sub units. Segmentation may take place by need (urgency, severity, trauma, body function) population characteristics (maternal and infant health, chronic condition, disability etc), focused hospitals (Military hospital, Trauma clinic, eye clinic, dental clinic etc.). 
(3) Customer Relation

Customer Relation means the relationship exists between care receivers and care providers. Patient choice is at the core of this relationship in case of health care BMC. Customer relationship in case of health care, vary from service to service. In our context of home care for elderly, the customer relationship may be long term. On the other hand, for any acute treatment the relationship may be of a daylong or few more days. Customer relationship also depends on the integration, coordination and process efficiency on part of the health care providers.

(4) Customer Channel

The customer channel refers to the medium through which the care provider provides services and maintains relationship with the existing patients (customers) as well as develops new customer relationship. This is a component which has a provision to use digital technology extensively. In case of present study, the use of digital medium to continuously monitor elderly in their homes is of outmost importance. Moreover, regional networks play a major role in health care distribution channel.

\section{(5) Revenue Model}

Revenue model is based on willingness-to-pay principle of health care consumers. Moreover, the potential sources of generating continuous flow of revenue by service providers/ entrepreneur is also discussed in this section. In terms of economics, revenue is cost plus profit. In case of health care business model, some key aspects of generating revenue are fixed allocation (monthly salary), Fee-for-Service (pay-per-procedure), Fee-for-episode (disease related services), Fee-for-membership (capitation), access fee etc. So revenue generation will depend on type of services provided. Higher the use of technology, lower the cost of producing services and higher the revenue generation.

These five elements constitute right-hand side of the business model. These elements are attributed to generate revenue from the business. The left hand side elements (discussed below) are however regarded as cost-generating component of business.

(6) Key activities

These are the major activities through which the business firm generates value to the customer. In case of health care, key activities are defined as coordination of various service processes which identifies actors of the systems, resources, bottlenecks etc. Key activities in health delivery system may vary widely from appointment management, respond to call, counselling to regular monitoring and therapies, care plan adjustment, follow-up service, encouragement etc.

\section{(7) Key Resources}

Key resources are most important assets required to produce and provide services to customers. Every resource has a capacity that may be utilized properly. Resources can be both tangible (physical, financial) and intangible (human, financial, intellectual). For health care delivery, physical resources may be hospital building, surgical equipment's, day care clinic etc. Human resources may be doctors, nurses, skilled medical staffs etc. Apart from these multi skilled teams, rapid access, prompt clinical decision making, experience may be considered as intellectual key resources of the business.

\section{(8) Key Partners}

Key partners are those who supply necessary materials and services required for smooth running of the business. If health care is considered as a network then there are three levels of key partners Macro-level (National Health System), Meso-level (regional supply networks of required medical products/ supply chain for physical goods)) and Micro-level (operations management and processes). Partnership is the key element in this context.

(9) Cost Structure

Cost incurred due to buying physical materials, establishing plant, paying for human resources and other avenues are listed under this sub-head.

\section{Integrated Home Care for Elderly: A Proposed Business Model}


Suppose an entrepreneur wants to start a health service business in a metro city. Providing integrated home care services to elderly staying alone or with elder spouse can be a motivation to run a business for the following reason.

1. Home-care service business is relatively new in the context of India where norms of 'Filial Piety' has strong cultural importance.

2. Since only a few entrepreneurs have started this business in India, new entrepreneur has greater opportunity to capture the market share through large scale investment.

3. Since the service is related to home care, physical establishment cost of the business is negligible.

4. Low investment is required. Hence, entrepreneur may earn high net profit.

5. Serving chronically ill elderly has a strong social value.

The first thing, the entrepreneur should think of is value proposition - i.e. how the targeted group of population, i.e. elderly will be benefitted from this business. While analysing value addition of the business, the entrepreneur must focus on (1) improving quality of life of chronically ill elderly through integration of a number of specialist treatment (2) providing psychological and spiritual support so that they consider themselves as an integral part of the society and most important (3) arranging for proper security measures through digital technology so that single elderly person or elderly couple stay protected in their homes.(4) Application of digital services(telemonitoringetc) so that the elderly patient may be able to contact the service provider whenever health emergencies arise.

The revenue generating right hand side of the canvas model includes customer segment, customer channel and customer relation.

\section{Customer Segmentation}

The entrepreneur may target those population group who are (1) chronically ill i.e. suffering from any chronic or age-related diseases such as diabetes, hypertension, cardiovascular diseases, respiratory diseases, neurological disorders, osteoporosis, visual and hearing impairment, cancer terminal stage and other types of disabilities (2) elderly group of people whose age is above 60 years (3) elderly people who stays alone or with his/her elderly spouse only. Following above criterion, the entrepreneur may be able to reach to the targeted group of population.

After identifying the group of targeted population for the business, now it is essential to get continuous flow of targeted patients through proper customer channel. It is the most important factor in any healthcare business model as it helps in getting maximum patient flow over time in a system. Since elderly people are generally not technologically advanced, hence building up customer channel through social media may not be very fruitful in this case. The entrepreneur may carry out health awareness camps and promotional events in different housing societies. The entrepreneur may also tie with hospitals, health check-up clinics, and religious centres in order to have continuous flow of targeted group of population. Advertisement on TV, radio and internet may also add to the flow of customers.

In order to retain the flow of targeted patient, it is mandatory for health care business to maintain a good customer relationship with the patient. In the case of home care business, a long term relationship is generally built up. However, for each services rendered to the elderly patient, it is very much essential to record post-service feedback on part of the patient. Even after completion of service period, follow up calls to elderly may add to good relationship with the patient. Apart from this, a $24 \mathrm{X} 7$ call centre along with mobile app service is required so that the elderly patients may be able to contact the service house whenever required or emergency situation arises.

All these three will constitute the revenue part of the model. A variant of revenue models are relevant in this context. Maximum amount of revenue can be generated from referrals and commissions. Access fee, membership fee are potential sources of revenue for this business.

The details of revenue structure are discussed below.

Revenue from Referrals - the service firm may refer patients to health check-up clinics, hospitals or may arrange everything on behalf of the elderly patient himself. Thus the service provider may be 
able to appropriate revenue from both the parties - referral/arrangement fees from patient and commission from concerned clinics/doctors/hospitals/pharmacies.

Revenue from membership - the service provider may charge annual/monthly membership fee from patients on the terms that the patient will get benefits round the clock.

Revenue from fee-per-service - every service provided to patients, may be charged individually as for example - installing security cameras, providing domestic workers, taking the patient to hospital or religious places etc. However the part of the revenue may be re-invested in the business and thereby the firm may take advantage of economies of scale in long run.

The main components of left-hand side of the diagram are key partners, key resources and key activities which in turn generate cost part of the model.

Key partners, in this business model, can be divided into two parts - one who supplies necessary materials to entrepreneur and who helps to smoothly run the business.

Banks and financial institutions are considered as primary key partners as they help to set up the business by providing necessary capital to the entrepreneur. Besides in order to smoothly run the home care business networking and collaboration is required with local government body, health equipment suppliers, security agency, pharmacy, ambulance and transport agencies, hospitals etc. however, the list is not exhaustive.

In order to provide integrated home care to elderly, coordination and managerial skill is considered to be the one of the primary Key Resources for this business. Since, care giving is at the centre of this business, the emotional side on part of the service provider, is also required to a large extent. Key sources can be physical or human- tangible or intangible. Physical resources are office building, service station, own transport vehicles etc. Human resources particular to this business, are doctors, nurses, health care professionals, managers, technicians, receptionists, marketing and finance professionals, domestic caregivers etc. Tangible resources are referred to all those resources which are used in daily proceedings - official and stationary products, computer and networking system, telephones etc. Intangible resources are managerial skill, goodwill etc.

The hint for Key Activities of this business has already been put forward in value proposition section. Assembling various services and thereafter providing a composite package of health as well as social services to elderly are two primary key activities of this business. Other activities includepreparing marketing and business expansion plan, revenue and cost management, maintaining long term relationship with existing customer, maximizing customer satisfaction etc.

In the process of producing services, costs are generated. Cost may be fixed or variable in nature. Establishment cost is considered as fixed cost. The cost which will vary according to the unit of services rendered is called Variable cost. Different component of costs for this business model are, wages to staff, office maintenance cost, marketing cost, rent, payment to specialist services, taxes, motivational budget etc.

\section{Conclusion}

This business model is explained particularly in the context of urban India because it is felt that cities of India are mostly based on nuclear structure of families where during the old age, at some point of time, most of the people experience living separately from their sons and daughters. However, this model is equally applicable in semi-urban or rural settings considering the demand potential for these kinds of integrated services in those areas. From business point of view, continuous investment in Research and Development is required for business innovation where there is a scope for extensive usage of digital technology. In this context, it is worth mentioning that government needs to come forward and join hand in hand with private health service provider. Because this kind of model may run well in Public-Private Partnership as large scale investment, efficient management and welfare 
considerations are preconditions for providing home care to elderly. Finally, in this paper an innovative business model is proposed where both care and technology are at the core of the model and much focus is needed on these two factors while setting up a health care service business, particularly for elderly.

\section{REFERENCES}

Census of India, 2011: www.censusindia.net

Jeyalakshmi, S., Chakrabarti, S., \& Gupta, N. (2011).Situation analysis of the elderly in India. Central Statistics Office, Ministry of Statistics and Programme Implementation, Government of India document.

Johnson, M. W. (2010). Seizing the white space: business model innovation for growth and renewal. Harvard Business Press.

Kimble, C. (2015). Business Models for E-Health: Evidence From Ten Case Studies. Global Business and Organizational Excellence, 34(4), 18-30.

Kodner, D. L., \& Kyriacou, C. K. (2000). Fully integrated care for frail elderly: two American models. International journal of integrated care, 1 .

Kringelum, L. B. (2015). A cognitive perspective on the antecedents of business model innovation: The case of the Port of Aalborg Authority. In DRUID Academy Conference.

Madigan, E., Schmotzer, B. J., Struk, C. J., DiCarlo, C. M., Kikano, G., Piña, I. L., \& Boxer, R. S. (2013). Home health care with telemonitoring improves health status for older adults with heart failure. Home health care services quarterly, 32(1), 57-74.

Morris, M., Schindehutte, M., \& Allen, J. (2005). The entrepreneur's business model: toward a unified perspective. Journal of business research, 58(6), 726-735.

Mouodi, S., Bijani, A., Hosseini, S. R., \&Hajian-Tilaki, K. (2016). Gender differences in the health status of elderly living alone compared to those who are not alone: Evidence of the AHAP study, North of Iran. Caspian journal of internal medicine, 7(2), 126.

Osterwalder, A., \&Pigneur, Y. (2009).Business Model Creation. Modderman Drukwerk: Amsterdam, The Netherlands.

Porter, M. E. (2010). What is value in health care? New England Journal of Medicine, 363(26), 2477-2481.

Russo, V., Ciampi, M., \& Esposito, M. (2015).A Business Process Model for Integrated Home Care. Procedia Computer Science, 63, 300-307.

Scanaill, C. N., Carew, S., Barralon, P., Noury, N., Lyons, D., \& Lyons, G. M. (2006). A review of approaches to mobility telemonitoring of the elderly in their living environment. Annals of Biomedical Engineering, 34(4), 547-563.

Scanaill, C. N., Carew, S., Barralon, P., Noury, N., Lyons, D., \& Lyons, G. M. (2006). A review of approaches to mobility telemonitoring of the elderly in their living environment. Annals of Biomedical Engineering, 34(4), 547-563.

Tseng, P. T., \& Chen, H. H. (2007).Reinventing healthcare service through m-care business model: the strategy analysis of WiMAX adoption. Journal of Communications, 2(5), 35-41.

Verstraete, T., \&Jouison-Laffitte, E. (2011).A conventionalist theory of the business model in the context of business creation for understanding organizational impetus. Management International/International Management/Gestiòn Internacional, 15(2), 109-124.

WIPRO (2012). Industry Outlook 2012: Care Management and the Future of Health. <www.wipro.com> 